\title{
Los judíos en el reino de Tolosa entre la tolerancia y el proselitismo arriano *
}

\author{
Ana María JimÉnez Garnica**
}

En los últimos años del siglo iv y comienzos del $v$ la Iglesia católica emprendió la tarea de concluir su sistematización teológica y dogmática, con la que los Santos Padres intentaban dejar claras las líneas comunes con el judaísmo y, sobre todo, sus numerosas discrepancias ${ }^{1}$. Esta empresa, con la que pretendian que ambas religiones quedaran bien diferenciadas ante los paganos, marcó el final de siglos de pacífica convivencia. Los cristianos adoptaron el principio universalista de la religión judaica y aspiraron, con ayuda de la legislación civil, a convertir a todos los habitantes del Imperio en ciudadanos de un estado ideológicamente ecuménico. La proclamación teodosiana del cristianismo como religión oficial en el año 391 supuso el punto de partida, a partir del cual paganos, judíos y herejes adquirieron la situación de minorías no permitidas. No obstante, la patrística occidental no olvidó nunca que Cristo y sus apóstoles habían sido inicialmente judios; lo que impelió a muchos de sus obispos a contraer una deuda de reconocimiento que se tradujo en un sentimiento de comprensión hacia el tradicionalismo judaico y en que, por estas fechas, raramente incitaran a sus comunidades a la violencia y al odio como era frecuente en el Mundo Oriental. Todos coincidian en lamentar la persistencia de los judíos en su ciego error $y$, animados por recomendaciones como las del obispo Agustín ${ }^{2}$, confiaban en atraerles a

* Comunicación presentada en el Encuentro Internacional de Historiadores «En torno a Sefarad". Toledo, 1991.

** (l. B. «Beatriz Galindo», Madrid).

La Iglesia y la Sinagoga tenian en común ciertas prácticas, tales como el matrimonio de clérigos y rabinos, el aniconismo de los lugares de culto, ciertos tabúes alimenticios, o la similitud en los cantos litúrgicos, de los que los cristianos eran indiscutiblemente deudores.

2 Blumenkranz, B., Die Judenpredigt Agustins. Ein Beitrag zur Geschichte der Jüdischristlichen Beziehungen in der ersten Jahrdunderten. Bâle 1946. Basler Beiträge zur Geschichtewissenschaft, t. 25: París 1973. 
la verdad mediante una actitud de bondad y amor, que intentaban hacer extensiva entre sus feligreses con sus escritos y homilias ${ }^{3}$. Fuera del área norteafricana encontramos por las mismas fechas un espiritu conciliador semejante en Roma y, en concreto, en el mosaico votivo de la iglesia de Santa Sabina ${ }^{4}$ (c. 422-432) que, tanto por su inscripción, como por la representación simbólica de la Iglesia (Ecclesia ex gentibus) y de la Sinagoga (Ecclesia ex circuncisione), ofrece una actitud respetuosa, exenta de caricaturas y propensa al acercamiento. En España sólo tenemos una noticia sobre actitudes violentas en la carta de Severo de Mahón, de dudosa fechación en el año $417^{5}$, además de los cánones conciliares del Elvira. $Y$ en la Galia, a comienzos del siglo $v$ no hay datos indicadores de ataques a las sinagogas o de cualquier otro tipo de persecución antijudaica.

Sin embargo, por la misma época se daba una disparidad de criterios ante el tema judaico entre la actitud civil y la eclesiástica. $Y$ fue entonces cuando, como continuación de la política constantiniana, se dictaron algunas de las leyes más perjudiciales para los judíos. Tales fueron la prohibición de ejercer cargos públicos, la de tener siervos cristianos y circuncidarlos - ambas del año $417^{6}$ - o la exclusión de la milicia del año 418 (C. Th. XVI, 8, 24), con las que se intentaba evitar que los judíos ejercieran cualquier dominio sobre los cristianos. Langmuir cree ver en ellas la influencia de los teólogos más radicales ante el problema judio ${ }^{7}$ $y$, en concreto, la del pensamiento de San Ambrosio, pero no podemos desigarlas de los esfuerzos hechos por Honorio para recabar ayuda de Constantinopla, sobre todo tras el asesinato de Estilicón, que había sido partidario de una generalizada transigencia religiosa ${ }^{8}$. Muerto ya Honorio,

3 Por ejemplo, las del prelado Quodvultdeus de Cartago, en la primera mitad del siglo $\mathrm{v}$, animaban a la práctica de la hospitalitas cristiana con todos los viajeros aunque se tratara de herejes o judios, a los que, en líneas generales, se prefería sobre los anteriores.

4 Blumenkranz, B., "Juifs et judaïsme dans l'art chrétien du Haut Moyen Âge", en Gli ebrei nell'alto Medioevo, Settimane di Spoleto 1978, 1980, pág. 989.

5 Ésta fue la fecha propuesta por G. Seguí Vidal (La carta encíclica del obispo Severo. Estudio crítico de su autenticidad e integridad con un bosquejo histórico del cristianismo balear anterior al siglo VIII. Palma de Mallorca, 1937), pero B. Blumenkranz la considera un falso de comienzos del siglo vII (Die Judenpredigt..., 1946, págs. 57-58).

6 Sin embargo una ley dos años anterior, del 415 (C.Th., XVI, 8,22) había permitido a los judios de Occidente tener esclavos cristianos.

7 LANGMUIR, G. I., "From Ambrose of Milan to Emicho of Leiningen: the transformation of hostility against Jews in Northern Christendom", en Gli ebrei nell'alto Medioevo, Settimane di Spoleto 1978, 1980, pág. 334.

8 Demougeot, E., "L'empereur Honorius et la politique antijuive", en Hommage à $L$. Hermann, Col. Latomus 44. Bruselas 1960, págs. 277-291. Así, por ejemplo, la prohibición de que los judíos enviaran el aurum coronarium (C.Th., XVI, 8,14) a Jerusalén se hizo para evitar la desviación del oro occidental hacia Oriente. 
el deseo de aproximación se convirtió en auténtica necesidad para Gala Placidia y su pequeño hijo Valentiniano III ante la usurpación de Juan (a. 423). Teodosio II restituyó a su primo en el trono pero, a cambio, impuso a un general de su confianza, Félix, y una ideología antijudaica que, pese a todo, no llegó a a alcanzar los niveles de intolerancia y violencia populares logrados en el llírico y Oriente. De ello se derivó la actividad legislativa que pretendió acabar con los judíos por consunción, como la famosa Novella de Valentiniano III del año 425 dirigida al Prefecto de Pretorio de las Galias, o la Novella III de Teodosio II del año 438. La primera les impedía el ejercicio de la abogacía, en adelante reservado exclusivamente para los católicos, y ratificaba la prohibición de ejercer como militares y poseer esclavos cristianos ${ }^{9}$; la teodosiana sancionó su actividad como defensores civitatis, y la construcción de nuevas sinagogas, con lo que se trataba de evitar el nacimiento de nuevas comunidades.

De los judíos de la Galia en el siglo $v$ tenemos muy rara información, lo que indica tanto su poca importancia numérica y económica, como que la práctica de sus tradiciones todavía no comportaba un problema ideológico. La Arqueologia, aunque parca en datos hasta el momento, discierne una presencia continuada, entre los siglos $I$ al $\mathrm{V}$, en algunos centros urbanos concretos del Sur. Y la información de las fuentes permite añadir que estaban integrados en ellos. Las zonas de hallazgos se centran en el valle del Ródano, preferentemente en torno a Lyon y Arles, y en el área de Burdeos, lo que coincide con una leyenda judía medieval ${ }^{10}$ que cuenta cómo, tras la conquista de Jerusalén, los romanos llenaron tres barcos de cautivos judíos y los hicieron a la mar sin capitán ni tripulación. Empujados por el viento, los tres barcos llegaron a las tres ciudades mencionadas, de forma milagrosa desde luego, puesto que ni Lyon ni Arles tenían puerto marítimo. Por su parte, una versión de Flavio Josefo informa que Herodes Antipas y Herodías fueron desterrados por Calígula a Lugdunum (Josefo, AJ, XVIII, 252), destino que, tanto si se trata de Lyon, como defiende Blumenkranz ${ }^{11}$, como si es la pequeña localidad meridional de Lugdunum Convenarum (St. Bertrand de Comminges), como apoyan la mayoría de los estudios recientes ${ }^{12}$, sigue dentro del área meridional gala. La Galia Narbonense fue, sin duda, la provincia de mayor

\footnotetext{
9 HAENEL, G., Novellae Constitutiones Imperatorum, col. 456.

10 Blumenkranz, B., "Les prémières implantations des juifs en France du ler au début du Ve siècle", Comptes rendus de l'Académie des Inscriptions et Belles Lettres, 1969, pág. 173; y Zunz, L., Literatur Geschichte der synagogalen Poesie. París 1865, pág. 17.

1 BLUMENKRANZ, B., "Les prémières implantations...", pág. 162.

12 Uno de los últimos en aceptarla es García IGLESIAS, L., Los judíos en la España Antigua. Madrid, ed. Cristiandad, 1978, pág. 45, n. 12.
} 
densidad demográfica judía, lo que tal vez haya que poner en relación con la importancia adquirida allí por el mitraísmo y las manifestaciones religiosas de raíz oriental. Se ha comprobado que otras comunidades judías del Mediterráneo Occidental, con rasgos similares a las del sur de la Galia ${ }^{13}$, incorporaron prosélitos de la religión mitraica y, con ellos, algunos de sus gestos y títulos rituales, como el de pater patrum, dando forma a una especie de sincretismo judeo-mitraico que debió tener gran éxito porque los autores cristianos medievales lo asumieron simplificándolo en el de Papa. El considerable número de hebreos de esa provincia se mantuvo durante la época visigoda, como veremos más adelante, y muchos de ellos, obligados por las comentadas restricciones legislativas, vieron en los diversos oficios generados por el comercio la forma de ganarse el sustento. Sus contactos con Oriente les determinó la necesidad de aprender griego, además del latín que era su lengua habitual, y del hebreo que era la litúrgica; y es de suponer que estas habilidades lingüísticas les hicieran cotizarse en los ambientes intelectuales ${ }^{14}$, donde la lengua griega era raramente conocida con las limitaciones de uso de los textos patrísticos orientales que ello conllevaba. Posiblemente por eso la incipiente literatura apologética gala, salida de las plumas de Próspero de Aquitania ${ }^{15}$, Salviano de Marsella, Sidonio Apolinar ${ }^{16} 0$ Cesáreo de Arles ${ }^{17}$ no sólo esté exenta de animosidad hacia los judíos, sino que deja traslucir vínculos de afecto sincero al que los hebreos supieron responder con su lealtad. Sidonio sentía por ellos la estima que se concede a las personas honestas ${ }^{18}$; y el obispo de Arles recomendaba participar en las comidas con los judíos (Serm. 1, 8), y los ponía como ejemplo ante los cristianos para que éstos mostraran su mismo celo en la observancia del domingo (Serm. 13,3). Pero no todos los intelectuales se preocuparon por conocerlos tan directamente. Juan Cassiano (cc. 360/365-433/434), por ejemplo, que desarrolló parte de su actividad catequética en Marsella, los identificaba con los nestorianos porque ambos negaban la divinidad de Jesús ${ }^{19}$; y la mayoría de los autores de finales del siglo iv y comienzos

13 Colaffemina, C., “Insidiamenti e condizione degli Ebrei nell'Italia Meridionale e Insulare", Gli ebrei nell'alto Medioevo. Settimane di Spoleto 1978, 1980, vol. I, págs. 197, 204 y ss

14 Sabemos que tanto el obispo Sidonio Apolinar, como su amigo Félix, senador de la Narbonense, emplearon a judios en puestos de responsabilidad (cf. SIDONIO APOLINAR, Epist. III,IV; IV,V y VI,XI).

15 Aquitania, Próspero de, In Ps., 106, v. 33 y 34, PL, 51, 309.

16 Epist. III,V y IV,V.

1" Courreau, J., "Saint Césaire d'Arles et les juifs", Bulletin de Littérature ecclésiastique, LXXI, 1970, págs. 92-112.

${ }_{13}$ Epist. VI,11 y VIII, 13.

19 De incarnat. dom.c.Nest. 4,10, PL 50,89. 
del siglo $v$ metían en un cajón de sastre indistintamente a judíos y herejes como objeto de sus tratados y sermones. Con ellos pretendían alertar a sus feligreses y darles suficientes recursos doctrinales para sus polémicas con sus vecinos hebreos.

Es muy probable que, además de en Burdeos, Arles y Narbona, floreciera otra comunidad judía en Tolosa, capital del reino visigodo. Ignoramos cuándo pudo nacer, pero parece lógico que no se formara con posterioridad al año 438 en que la novella teodosiana prohibió construir nuevas sinagogas, ni al 507, cuando los francos, católicos, ocuparon la ciudad. Por tanto, debían de esta ya en ella cuando llegaron los visigodos y permanecieron al menos hasta el siglo $x 1^{20}$. Armand Lunel ha ubicado otras sinagogas en Béziers, Lodève, Lunel, Mende, Montpellier, Nîmes, Pamiers, Pézenas, Pesquières y Saint-Gilles, entre otros lugares; pero no las sitúa cronológicamente ${ }^{21}$.

Los judíos no constituían una raza biológica extraña al ambiente ga$10^{22}$; hablaban latín, no se diferenciaban en la indumentaria, y muy poco en las costumbres diarias, salvo en ciertas normas alimenticias. Estaban integrados en el conjunto de la ciudadania y, a diferencia de lo que ocurría en Oriente, no se les consideraba extranjeros. Por todo ello es probable que vivieran en barrios segregados a modo de guetos ${ }^{23}$, aunque las normas de desplazamiento para el cumplimiento del sabbath les obligaran a vivir en zonas próximas a la sinagoga. Todo lo cual no quiere decir que les faltaran detractores. En el año 417, el senador pagano Rutilio Namaciano se lamentaba de que la nación vencida oprimiera entonces con sus leyes a sus vencedores (victores que suos natio victa premit). Aunque es probable que esta queja concreta fuera dirigida contra el grueso de judíos

20 Según la tardia Vita S. Theodardi (c. 5. AA. SS. Mayo, 1, 1, 143) los judios de Toulouse abrieron la ciudad a los árabes. Como castigo, Carlomagno ordenó que, cada año, en las tres festividades principales, un judío de la ciudad se presentara a las puertas de la catedral para ser golpeado públicamente (el soufflet). Es probable que el hagiógrafo confundiera la invasión de los sarracenos, que nunca tuvo lugar, con la de los normandos del año 848 (cf. KATZ, S., The Jews in the visigothic..., pág. 117). Otras narraciones medievales recogen también esta costumbre de los ciudadanos de Toulouse con los judíos, así como la muerte de otro, apaleado, en el año 1017, por haber insultado la liturgia cristiana (LIFSCHITZ-GOLDEN, M., Les juifs dans la littérature franãise du moyen âge (mystères, miracles, chroniques). NUeva York, Inst. of French Studies, Columbia University, 1935, pág. 84).

${ }_{21}$ Lunel, A., Juifs du Languedoc, de la Provence et des Etats franãis du Pape.París, Albin Michel, 1975, pág. 14.

22 lbidem, pág. 10.

23 Las juderias no se conocen hasta Plena Edad Media, a excepción del caso de Alejandria recogido por FILón (In Flaccum, 8, 53-57, 123-129, 134, etc.) donde, en el año 38, al considerar sus habitantes que los judíos eran extranjeros, les obligaron a vivir reunidos en uno de los cinco barrios de la ciudad (cf. Cracco Ruggini, L., "Pagani, ebrei e cristiani...”, págs. 31-32). 
y cristianos, entre los que no veía diferencia, al comprobar el cambio sufrido por las antiguas costumbres. Rutilio sentía auténtica aversión hacia los primeros a quienes consideraba raza inmunda (debita genti) ${ }^{24}$. Su caso es excepcional y, en general, los intelectuales paganos fueron defensores de la tolerancia religiosa y de la convivencia pacífica de todas las fes para poder así asegurar su propia supervivencia ${ }^{25}$. De hecho, la reiteración de las mismas sanciones en los cánones conciliares galos que median entre el año 465 (Concilio de Vannes) al año 888, indican que el contacto entre judíos y cristianos era estrecho, que se seguían practicando los matrimonios mixtos, que los judíos seguían poseyendo siervos cristianos, y que los clérigos participaban en comidas con ellos. Esta última costumbre, que en un principio a la Iglesia le resultó agradable, se tornó odiosa y fue reiteradamente prohibida desde el citado concilio bretón de Vannes ${ }^{26}$. Fruto de esa convivencia fue el que en la Galia se usaran con profusión algunos de los símbolos judíos más representativos (la menorah, por ejemplo), aunque muchas veces estarían privados de su original significado religioso ${ }^{27}$. La idea parece confirmada por Sidonio Apolinar cuando describe el castillo del noble aquitano Pontius Leontius ${ }^{28}$ en el que había un panel pintado con la historia del origen de los judíos circuncisos que, en opinión de Sidonio, "resplandece para la eternidad». En el ambiente aristocrático del escritor, los judios eran parte del Imperio y, su historia, un episodio más.

Los textos hagiográficos ofrecen muestras que prueban la buena convivencia de judios y cristianos. En el año 449 los judíos de Arles participaron en los funerales del obispo Hilario con lágrimas y gemidos ${ }^{29}$, junto a los fieles del prelado, e incluso cantaron salmos en su propia lengua litúrgica hebrea. De forma parecida actuaron a la muerte de Santa Rustícula ${ }^{30}$, así como a la del obispo Cesáreo en 549 , en la que cuentan sus biógrafos cómo clamaban junto con los cristianos: «iQué desgracia, que el mundo no pudo conservar por más tiempo a tal protector y guía!" ${ }^{31}$. Dos años después, en 551, cuando murió el obispo Gallus de Auvernia y sus reliquias fueron transportadas a la basílica de San Lorenzo, los

24 Reditu suo, I, 387

25 Así lo propuso el senador Symmaco en su famoso discurso (Rel. Ill, 10, año 384 d.C., $M G H, A A, V I$, pág. 282).

${ }_{26}$ Blumenkranz, B., "ludaeorum convivia. À propos du concile de Vannes $(465)$, c. 12 ", en Etudes du droit canonique dédiées à G. Le Bras, II. París 1965, págs. 1055-1058.

27 BlumenKranz, B., "Les prémières implantations des juits...", pág. 167.

2B Carmen, XXII, 201.

29 Honorato, Vita Hilarii, c. 29. PL, 20, col. 1242-1243.

30 Honorato, Vita Rusticulae, c. 25, MGH, ss.rr.mm., IV, pág. 350

31 Vita Caesarii, II, 49, PL, 67 
judios se unieron a la procesión portando antorchas ${ }^{32}$. Todas estas alusiones prueban el trato correcto de los obispos con los judíos, comportándose como auténticos pastores al intentar atraer al rebaño a las ovejas desorientadas y perdidas.

Honorio entregó a los visigodos en el año 418 las regiones meridionales galas de Aquitania 1 y $\|$ donde se ubicaba Burdeos, además de Toulouse, que pertenecía a la Narbonensis, región que terminaron por incorporar también a su reino y, con ella, las ciudades de Arles y Narbona. Por tanto, desde el primer momento tuvieron contacto con los judíos que vivían en el área controlada militarmente por ellos. Hacía poco más de cuarenta años que las magistraturas tribales godas, obligadas a refugiarse en el Imperio, habían tenido que sustituir el soporte religioso de su antiguo paganismo por el arrianismo profesado, entonces, por el emperador Valente (a. 376). Fue una conversión impuesta desde arriba a toda la colectividad de las tribus, sin que éstas pasaran previamente por un convencimiento dogmático, por lo que entendieron las nuevas creencias, "de acuerdo con las suposiciones de la religiosidad germánica" ${ }^{33}$, sin romper de raíz con todas las anteriores. Sería con el paso del tiempo, la situación de religión perseguida y, sobre todo, la organización de su Iglesia Nacional, lo que les hizo convertirse en verdaderos arrianos, desarrollar una jerarquía paralela a la ortodoxa, lanzarse al proselitismo ${ }^{34}$, e instruirse en el pensamiento doctrinal arriano. Es probable que, mientras iniciaban su reinado en la Galia y comenzaban a difundir el arrianismo entre los nacientes reinos germanos, intentaran que renaciera el esquema de los tria genera ${ }^{35}$. Pero, una vez que los godos organizaron su Iglesia Nacional, reivindicando para ellos la verdadera fe que defendía con sus escritos el obispo Maximino ${ }^{36}$, el equilibro se rompió, pues en su Iglesia arriana,

32 Tomado de Katz, S., The Jews in the Visigothic and Frankish Kingdoms of Spain and Gaul. Cambridge, Massachusets 1937, 2. ${ }^{\circ}$ ed., Nueva York 1970, pág. 33.

${ }_{33}$ LANGMUIR, G. 1., «From Ambrose of Milan to Emicho of Leiningen...", pág. 336.

34 Thompson, E. A., "El cristianismo y los bárbaros del Norte", en Momigliano, A., El conflicto entre el paganismo y el cristianismo en el siglo IV. Madrid, Alianza, 1989, págs. $71-94$ y especialmente págs. 85 y ss.

${ }_{35}$ En el siglo 11 los apologistas cristianos habian difundido el modelo de los tria genera (paganos, hebreos y cristianos) para evitar que los paganos les consideraran una variante del judaísmo (Cracco Ruggini, L., «Pagani, ebrei e cristiani: odio sociologico e odio teologico nel mondo anticom, Gli ebrei nell'alto Medioevo. Settimane dispoletos, 1978, 1980, vol. 1, pág. 25), pero con posterioridad lo abandonaron por el de la universalidad católica. Los arrianos, con los paganos y otras sectas religiosas porfiaron por mantener su individualidad, dentro de un respeto mutuo, sobre todo en el periodo comprendido entre la muerte de Graciano (año 384) y el edicto teodosiano del año 391.

${ }_{36}$ Maximinus, In Matthaeum, XII, 10; citado por Mestim, M., Les Ariens d'occident, 335-430. Paris 1967, pág. 348 . 
Iglesia de Perfectos y Santos, los demás no tenían cabida. Así, tras un período de tolerancia con las otras formas ideológicas, se caminó hacia la uniformidad cuando la Iglesia Madre arriana, unitaria y ecuménica, pretendió reunir a su alrededor a judíos y paganos convertidos ${ }^{37}$.

Los godos no se integraron desde un primer momento con los galorromanos pues, pese a la romanización parcial de los hombres por sus contactos con el ejército, sus familiares se comunicaban en lengua goda -inicialmente al menos- y tenían los hábitos alimenticios propios de un pueblo en desplazamiento casi continuo durante cerca de medio siglo. Por tanto, era difícil que un galo sentara a su mesa a un godo. Se daba por añadidura el sentimiento de expolio que afectaba a los propietarios que habían visto mermadas sus posesiones. Además, los godos eran étnicamente extraños en la Galia, y más dada la diversidad de sus componentes, entre los que también había asiáticos.

Entre los visigodos y los judios existían nexos suficientes como para que no pasaran inadvertidos y fueran considerados miembros integrantes del reino cuando Alarico II decidió legislar para todos sus súbditos, a comienzos del siglo vi. En primer lugar, judíos y arrianos formaban minorias no permitidas. Esta situación favoreció el desarrollo de sendas mentalidades hebraica y arriana ${ }^{38}$, mucho más fuerte en cualquier caso entre los primeros, puesto que los godos terminaron por asumir el arrianismo como distintivo étnico. Los judíos ganaron inexplicablemente muchos adeptos durante el siglo $v^{39}$, pese a las normas legislativas en vigencia que les excluían de participar en la vida pública y que hacían nada envidiable la pertenencia a esta religión. Su proselitismo debió ser tan eficaz que, a partir de finales del siglo $\mathrm{v}$, los teólogos utilizaron todas las armas a su alcance para evitar el contacto entre los niceanos y todos los que estuviesen en el Error.

Arrianos y judíos comulgaban también en la tendencia a enfatizar a un solo dios, el Padre, despreciando ambos la figura de la Santísima Trinidad, a la que consideraban casi como un politeísmo ${ }^{40}$. Les unía igualmente la

37 Maximinus, Opus imperfectum, 895. Maximino ejemplificaba esta idea usando la figura de la gallina y sus polluelos. Es posible que sea éste el significado del, hasta ahora, enigmático grupo conservado en la catedral de Monza.

38 Steinhaus, F., Ebraísmo sefardita. Bolonia 1969, pág. 5.

39 Braude, G., Jewish Proselyting. Providence 1940, pág. 25.

40 Langmuia (“From Ambrose of Milan...», pág. 339, n. 41) comparte con Blumenkranz la idea de que los germanos de Occidente se esforzaron por imponer un cristianismo abiertamente monoteísta; frente a la opinión de JunmanN, J. A., (Liturgische Erbe und Pastorale gegenwart. Insbruck 1960, págs. 30-44) que opina que, los germanos, al encontrarse todavía a medio camino entre el paganismo y el cristianismo, aceptaron el arrianismo como forma de seguir creyendo en dos o tres dioses jerarquizados. 
convicción de ser, cada uno por separado, pueblos elegidos, los únicos profesadores de la verdadera religión y, por ello, perseguidos y dispersados ${ }^{41}$. La obra del obispo arriano Maximino apoyaba este pensamiento. Además, ambas comunidades tenían en su historia un período migratorio de cuarenta años llenos de esfuerzos, penalidades y batallas tras los cuales los judios habían conseguido en el pasado la Tierra Prometida y los visigodos habían recibido Aquitania. Y así como Moisés había sido el jefe capaz de lograr dicha empresa con los judíos, Ulfilas fue el admirado héroe de los arrianos porque había sacado de la Gothia a los cristianos perseguidos por sus parientes godos, guiándoles más allá del Danubio, como «si se tratase de un nuevo paso del Mar Rojo hacia la libertad", dice Cracco Ruggini ${ }^{42}$. El paralelismo se acentuaba aún más por el hecho de que durante esta época de desplazamiento las estructuras sociales de ambos seguían basadas en la familia y la tribu. En el ámbito religioso, judíos y arrianos compartían una religiosidad orientada más bien hacia el ritual que a la contemplación ${ }^{43}$. Éste fue un eficaz medio de proselitismo religioso judío y el aspecto que más temían las otras religiones de la hebraica. A los judíos se les obligó a cambiar el emplazamiento de sus sinagogas siempre que sus cantos se oyeran en las iglesias próximas ${ }^{44}$, y los apologistas cristianos criticaron los cantos procesionales, o las actividades litúrgicas realizadas fuera del edificio de culto ${ }^{45}$, que para los judíos eran útiles instrumentos propagandísticos. Con el incremento alarmante de prosélitos la tensión antijudaica ganó en intensidad, por lo que, a partir de finales del segundo tercio del siglo $\mathrm{v}$, los cánones conciliares galos y la literatura hagiográfica y dogmática comenzaron a ocuparse de ellos más frecuentemente, dejando traslucir un odio social, raro hasta entonces en Occidente ${ }^{46}$. Se multiplicaron los tratados didácticos, las controversias literarias (altercationes), las homilias y los diálogos que, bien leídos o escuchados, tenían la misión de salvaguardar entre los creyentes la pureza de la ortodoxia. Incluso se sesgó información anterior. Tenemos un ejemplo en la mencionada Vita del obispo Cesáreo de Arles. En el

41 Teodosio dispersó por Oriente a los godos que habían cruzado el Danubio para quitarles fuerza militar. Cf. THOMPSON, E. A., "The visigoths from Fritigern to Euric", Historia, XII, págs. 105-126; Y AMIANO MaRCELINO, XXXI.

42 Cracco Ruggini, L., “Pagani, ebrei e cristiani...”, pág. 70.

43 LANGMUIR, «From Ambrose of Milan...”, pág. 339.

${ }_{44}$ Cf. Gaegorio Magno, Epist. 2,6 (año 591), referente a los judíos de Terracina que molestaban con sus oficios litúrgicos a la iglesia próxima.

${ }_{45}$ Gregorio MAgno, Epist. 3,37 (año 593) refiere el caso de un judío de Sicilia que había construido un altar dedicado al profeta Elías donde llevaba a muchos cristianos para participar de su culto.

${ }^{46} \mathrm{Ct}$. Simon, M., Verus /srael. Etude sur les rélations entre chrétiens et juifs dans l'empire romain (años 135-425). Paris 1964, págs. 356 y ss. 
Libro I (col. 1011-1012), redactado por Cipriano de Toulon a mediados del siglo VI, cuando la polémica antijudía era manifiesta, se cuenta que, en el año 508 , los judíos denunciaron al obispo ante las autoridades godas y le acusaron de haber querido entregar la ciudad de Arles a sus sitiadores burgundios. Aunque la inocencia del prelado quedó demostrada, Cipriano no se cuestión la reacción hostil de los judios, reacción pasajera por otra parte, - puesto que años después los hebreos lloraron su muerte- $y$, para nosotros, igualmente lógica al ser consecuencia de la reciente legislación canónica (Concilio de Agde) y civil (la Lex Romana Visigothorum) del año 506 por las que los judíos resultaron perjudicados ${ }^{47}$. No debemos olvidar que en ninguno de los documentos conciliares de la provincia Narbonense anteriores a la segunda mitad del siglo $\mathrm{V}$ (Nîmes, a. 394; Orange, a.441; y Vaison, a. 442) se alude al problema judío, por lo que es lógico que toda esta actividad legislativa les inquietara ${ }^{48}$. Lo único que preocupó a Cesáreo fue evitar el incremento de prosélitos judíos y arrianos forzados por la derrota, y por eso, vendió objetos de la Iglesia ${ }^{49}$ para poder comprar esclavos burgundios y francos y evitar así que, al entrar al servicio de los visigodos, de los ostrogodos o de los judíos, fueran obligados por sus amos a adoptar sus respectivas religiones. También es fácil que la actitud del obispo con los hebreos se modificara con el cambio de centuria, pues frente a la posición cálida y afable de los sermones comentados más arriba, encontramos otra más desconfiada en los cánones del Concilio de Agde que él presidió. Inició con él otra etapa, más polémica, en la que probablemente haya que incluir también un sermón sobre la Iglesia y la Sinagoga, la primera obra claramente antijudia que se conoce en la Galia ${ }^{50}$. Otros hagiógrafos del siglo vi, al escribir sobre personajes anteriores, dejaron filtrar detalles poco propios del momento que estaban historiando. Por ejemplo, cuando Venancio Fortunato redactó la biografía del obispo Hilario de Poitiers $(+366)$ indicó, como dato de su santidad, que negó el saludo a los judíos ${ }^{51}$ y que nunca comió con ellos, defendiendo una actitud opuesta a la comprensiva que, como hemos visto, se mantenía en los siglos anteriores. A medida que avanzaba el siglo vi, las noticias de las fuentes sobre los judíos aumentaron notable y alar-

${ }^{47}$ Sin embargo Courreau, J., "Saint Césaire d'Arles et les Juifs", Bulletin de Littérature ecclésiastique, LXXI, 1970, pág. 112, no cree que el contenido de sus sermones ni uotras medidas tomadas por este obispon fundamentaran tal violencia.

${ }_{48}$ Sólo se alude a ellos en los Statuta Ecclesiae antiqua (de hacia el 475) documentos que, más que mencionar a los judíos, previenen a los cristianos de la tendencia a judaizar.

${ }_{49}$ Vita Caesarii, I, 32, col. 1012, PL, 67. Una carta de Gregorio Magno (Epist. 1,66) del año 591 nos informa de que las ventas de los objetos litúrgicos estaban prohibidas.

5o Sermo CIV, Corp. Christ., t. CIII, págs. 429-433.

51 Vita S. Hilarii, c. 3. MGH, aa, IV, 2, 2. 
mantemente, síntoma de que el problema hebreo ya afectaba a la corriente de opinión como consecuencia de la difusión general de la ortodoxia en Europa ${ }^{52}$. Los cristianos rechazaron a los judíos incluso visualmente hasta el punto de obligarles a la reclusión desde el Martes Santo al Domingo de Resurrección ${ }^{53}$. Sólo Gregorio Magno se mantuvo constante en la tolerancia y comprensión tradicionales de la Iglesia de Occidente, y consiguió que los judíos de Italia disfrutaran de una relativa tranquilidad frente al agitado cuadro político general ${ }^{54}$. A medida que adquiría forma en Europa la nueva civilización germánica-cristiana, el elemento universalista judío dejaba de tener cabida.

Los visigodos del reino de Toulouse tenían un concepto tribal de la religión e inicialmente admitieron la convivencia con otras creencias, siempre que no afectaran la base firme sobre la que ellos mismos se asentaban ${ }^{55}$. No sabemos que hicieran propaganda religiosa arriana fuera de los otros reinos germanos sobre los que pretendieron ejercer su superioridad.

La herejía arriana había participado en la actividad apologética antijudaica con un importante tratado sobre los judíos, el Tractatus contra ludaeos ${ }^{56}$. Su autor, el obispo arriano Maximino, lo escribió en fecha tem-

52 Para PARENTE, F., ( secolo", Gli ebrei nell'alto Medioevo, Settimane di Spoleto 1978, 1980, pág. 635) el aumento de intensidad de la polémica antijudaica se debe al descenso del nivel cultural general. Su argumento no es admisible, al menos, para el reino visigodo hispano (cf. ORLANDIS, J., La vida en España en tiempo de los godos. Madrid, Rialp, 1991, págs. 66-83), muy fructífero culturalmente y donde, sin embargo, se produjeron las persecuciones más violentas y efectivas del Occidente temprano-medieval

${ }_{53}$ Concilio III de Orléans del año 538, c. 33 , cuyas medidas fueron ratificadas por Childeberto I (Childeberti I regis praeceptum, MGH, Leges, I,1).

${ }^{54}$ Colorni, V., "Gli ebrei nei territori italiani a nord di Roma dal 568 agli inizi del secolo XH'», Gli ebrei nell'alto Medioevo, Settimane di Spoleto 1978, 1980, pág. 242.

${ }_{55}$ Ésta fue una constante en la historia religiosa de los visigodos. Antes de la conversión los jefes tribales persiguieron a los cristianos porque su nueva ideología rompia la unidad social de la tribu. También lo entendió así el resto de la tribu a la que no le importó simular una comida ritual con carne no consagrada en la que pudieran participar los cristianos (Passio $S$. Sabae, ed. Delehaye, Analect a bollandiana, XXXI, 1912, págs. 216-221). De forma similar Leovigildo pretendió que toda la gente por él gobernada tuviera una única relación con Dios, por lo que se esforzó por establecer una religión sin límites rígidos. Otro tanto podemos decir de aquellos reyes germanos (visigodos, francos y lombardos) que obligaron a los judíos a bautizarse: lo hicieron partiendo de la misma idea de dar una sola base religiosa a todo el cuerpo social. Ésta no fue comprendida fuera del grupo germano. Gran parte del clero la reprobó por su forma violenta de aplicación.

se PL 57, 793-806. Edición crítica en Tuaner, C. H., Journal of Theological Studies, $n .^{\circ} 20$, 1919, págs. 293-310. Este tratado fue atribuido por error a Maximino de Turín, pero Dom Capelle ("Un homéliaire de l'evêque arien Maximin", Revue Bénedictine, n. ${ }^{\circ} 34,1922$, págs. 81-108) se lo restituyó al obispo arriano Maximino. 
prana, entre 427-428. Aunque ignoramos sus motivos, cuesta trabajo pensar que lo hiciera por mimetismo con los niceanos, y más bien pensamos que fuera por adoptar una postura defensiva ante el atractivo ejercido por el judaísmo en África, adonde marchó con el conde Sigiswult con la misión de hacer propaganda arriana. Uno de los capítulos más interesantes es el IV, en el que aborda el tema de la circuncisión, mutilación del cuerpo rechazada por él con horror por ser marca infamante, y a la que niega su garantía de salvación, a no ser -dice- que ésta les sea omitida a las mujeres (capítulo Vl). Para Maximino la circuncisión es sólo una señal de raza y, consecuentemente, el hombre se salva sólo por la pureza de su corazón. Este polémico tema estaba de actualidad a raíz de la reciente publicación (a. 417) por Teodosio II y Honorio de la ley que prohibía a los judíos circuncidar a sus siervos cristianos. Evragio, escrito galorromano, casi desconocido, de mediados del siglo v, usó en su altercatio argumentos parecidos ${ }^{57}$ y Rutilio Namaciano les consideraba raza inmunda porque «mutilan sin piedad la extremidad del miembro genital», lo que para él era una «locura» y una "extravagancia» propias de una "banda de esclavos impostores" 53 . Cabría preguntarse por qué en una época en la que el cuerpo humano comenzó a perder valor, la oposición antijudaica rechazó de plano la mutilación de la circuncisión. Tal vez se debiera a que, en la primera mitad del siglo $v$ todavía se tendía a distinguir entre la legislación civil y la religiosa, contando cada una con sus propias sanciones. Ia Ley del Nuevo Testamento no podía permitir una práctica cruenta, frecuente por el contrario en el terreno de lo estatal y lo profrano, y más cuando esa práctica acabó por convertirse en un distintivo de los hombres libres frente a los esclavos.

La obra del arriano Maximino fue muy admirada en la corte ostrogoda, donde Teodorico mandó que se hicieran copias en el scriptoriu $m$ de Verona. Hoy se conserva, incluido el Tractatus contra ludaeos, en el Codex Veronensis $\mathrm{LI}$, fechable entre fines del siglo $\mathrm{V}$ y principios del siglo VI. Ignoramos hasta qué punto los arrianos de Tolosa siguieron también su doctrina y cuánto pudo influir dicho tratado apologético en su comportamiento hacia los judíos. Es fácil que en el reinado de Teodorico ll se dejaran sentir sus ecos ${ }^{59}$, pero es mucho más probable aún que ocurriera durante el reinado de Alarico II quien, casado con la princesa ostrogoda

57 Altercatio Simonis ludaei et Theophili christiani, $P L, 20$, col. 1165-1182.

58 Reditu Suo, I, 387-391.

59 El estudio iconográfico de los mosaicos de la Iglesia de la Daurade parece apuntar a una posible influencia del pensamiento del obispo Maximino (cf. JIMÉNEz GARNICA, A. M., «El arte oficial en el reino visigodo de Tolosa: la Daurade”, Archivo Español de Arqueología, 1988, págs. 179-196). 
Thiudigoto, cayó bajo la órbita de la dinastía amala hasta el punto de imponer a su primogénito el nombre de uno de sus héroes fundadores. De hecho, es de este reinado del único período del que tenemos información directa sobre los judíos. No obstante, Sidonio Apolinar da una pequeña información que resulta de interés cuando, al narrar cómo eran las comidas del rey Teodorico II, menciona el lujo de su mesa en los días de sabbat, aunque prefiere no hacer comentario sobre ello ${ }^{60}$. ¿Quiso dar a entender que los arrianos comenzaban a judaizar algunas de sus costumbres? Hoy por hoy no tenemos más datos que nos permitan dar una respuesta afirmativa.

Los judíos galos, por su parte, no debían tener importantes teólogos o rabinos con sólida formación doctrinal, capaces de elaborar una literatura que defendiera su postura, aunque no hay que descartar que ésta se hiciera desaparecer con posterioridad, como ocurrió también con la arriana ${ }^{61}$.

El ostrogodo Teodorico practicó con los judíos de su reino una política de tolerancia religiosa, que se tradujo en su negativa a imponerles la fe por la fuerza ${ }^{62}$ y en su afán porque gozaran de una situación justa, no pagaran impuestos especiales ${ }^{63}$, y que la ley los defendiera siempre que sus intereses resultaran lesionados ${ }^{64}$. Consciente de su lealtad política, eligió incluso a uno de ellos, a Symmaco, como colaborador en las tareas legislativas ${ }^{65}$.

Lamentablemente del reino tolosano no se conserva una documentación diplomática similar a la del ostrogodo, tan abundante de información, lo que, para estudiar a los judíos, nos obliga a limitarnos a las menciones del Concilio de Agde, a las alusiones en la Lex Romana Visigothorum, y a algún dato suelto de origen hagiográfico ${ }^{66}$. Por lo que respecta a las normas sancionadoras legislativas, son reiteración de otras romanas an-

60 SidONIO, Epist. I, II, 6

61 En el siglo vi conocemos el caso del judio Prisco, joyero de la corte de Chilperico, que se enfrentó en una discusión apologética con Gregorio de Tours, siendo encarcelado por negarse a aceptar el bautismo.

62 CASSIOdORo, Variae, 2, 27 (años 507-511).

63 Cassiodoro, Variae, $5,37$.

64 Anonymus Valesianus, pars post. 14, 82 (año 519), MGH, aa, IX, 1, pág. 326. Para Teodorico la religión era parte de la política, por eso cuando redactó su Edictum lo hizo para que fuera cumplido por todos sus súbditos: godos, romanos, arrianos, ortodoxos y judíos, como queda especificado en el epílogo del documento

65 Anonymus Valesianus, pars post. 15, 94-95, MGH, aa, IX, 1, pág. 328.

66 De ahí la brevedad con que la bibliografía moderna ha tratado el periodo anterior a la conversión. Entre las obras generales más recientes destaca BACHRACH, B. S., Early Medieval Jewish Policy in Western Europe. Minneapolis, 1977 que le destina sólo de la pág. 3 a la 5. 
teriores, aunque en número reducido. Mas no debemos contentarnos con la visión negativa y un tanto deformada que proporciona su lectura. Las menciones de los obispos y la noticia de la defensa de Arles ofrecida por la Vita Cesarii nos muestran a unos hebreos integrados en sus ciudades y afectos al régimen que las gobernaba y que les permitía libertad relativa para practicar su religión y su culto. Además, las relaciones entre Alarico Il y Teodorico el Grande les garantizaron la viabilidad del mar Mediterráneo y el contacto con las comunidades judías de Italia y Palestina ${ }^{67}$. De ahí la opinión defendida por Blumenkranz de que, hasta el Concilio III de Toledo (a. 58 9), fecha de la conversión de Recaredo con todo su pueblo, judíos y arrianos habían sido, en la mayoría de los casos, aliados naturales ${ }^{68}$, por lo que hay que considerar esta fecha como la más trágica de la historia del pueblo hebreo ${ }^{69}$.

Hay una unanimidad entre la mayoría de los autores sobre la tolerancia de Alarico ll con los judios, que alguno ${ }^{70}$ ha llegado incluso a calificar de «liberalidad sorprendente». Pero, en realidad dicha tolerancia no fue más allá del significado estricto del sustantivo: el rey visigodo permitió la coexistencia en su reino del judaísmo y la ortodoxia cristiana junto con el arrianismo, mientras que condenó a eunomianos, priscilianos y maniqueos. A los hebreos no les dio trato alguno de favor y se limitó a adoptar la misma actitud que su suegro, evitando que pagaran impuestos especiales (el Breviario no incluyó el aurum coronarium) y procurando que conservaran su autonomía judicial en cuestiones religiosas (L.R.V. II, 1, 10). Por lo demás, si en su Código sólo incluyó 10 de los 50 preceptos legales contra los judíos existentes en la compilación teodosiana (además de la Novella III de Teodosio y de las Sententiae de Paulo), no fue porque aboliera los restantes $40^{71}$, sino porque sus legisladores consideraron vano recoger antiguas leyes prescritas o revocadas. Alarico en ningún caso pretendió ofrecerles una situación mejor de la que habían disfrutado con el Imperio ${ }^{72}$. Les mantuvo la prohibición de poseer esclavos cristianos por procedimientos que no fueran sucesión y fideicomiso, y la de comerciar con ellos (L.R.V. XVI, 4, 2). Asimismo, en to que respectaba a

67 Colaffemmina, C., "Insediamenti e condizione degli ebrei...», pág. 226.

6a Blumenkranz, B., Les auteurs chrétiens latins du Moyen Age. Sur les juifs et le judaisme. París-La Haya 1963, pág. 18.

69 Blumenkranz, B., Juifs et chrétiens dans le monde Occidental, 430-1096. París-La Haya 1960, pág. 105.

${ }_{70}$ Thompson, E. A., Los Godos en España. Alianza, 1969, pág. 69.

71 Thompson, E. A., Los Godos..., pág. 68.

72 JUSTER, "La condition légale des juifs sous les rois wisigoths", en Études d'histoire juridique offertes à Paul Fréderic Girard, II, 1913, pág. 273, n. 4. 
cargos públicos, les aplicó la Novella III de Teodosio II del año 438 por la que les prohibía recibir cualquier honor derivado de un cargo administrativo, ejecer como defensor civitatis, praeses y patronus; también se les prohibía ser abogados o militares, lo cual no fue óbice para requerir su colaboración en casos de gravedad extrema; y se les obligaba a aceptar las cargas de la curia. Tampoco se les permitió ser guardianes de prisión para evitar que, en el ejercicio de su tarea, hicieran daño a los cristianos. Por otra parte, les excluyó su antiguo derecho a la autonomía de mercado que les había sido respetado por los emperadores cristianos ${ }^{73}$. En resumen, se puede decir que el espíritu del Breviario alariciano es claramente discriminatorio con los judíos, a quienes se intentó seguir lesionando en sus derechos civiles frente a los cristianos, con lo que los últimos años de gobierno del Rey visigodo se convirtieron en el prolegómeno de las futuras y terribles persecuciones judaicas.

Por lo que respecta al ámbito de lo religioso, Alarico no quiso asestar un golpe definitivo a la ideología hebraica. En aplicación de la mencionada Novella III de Teodosio II, el rey visigodo les aseguró sus privilegios religiosos, al permitirles mantener y reparar sus sinagogas (aunque sin embellecerlas, ni construir otras), el culto y sus cementerios. Sancionó la infracción con la exagerada cifra de 50 sueldos de oro e incluyó en la Interpretatio la obligación de que el edificio ilegalmente construido se convirtiera en iglesia católica. También quedó garantizada la observancia del sabbath (L.R.V. II, 8, 3), día en que no se podía emprender acción judicial alguna contra los judios, ni tampoco ser obligados a realizar ningún tipo de labor. La misma prohibición alcanzaba al resto de las festividades judías. En cambio, tomó todas las medidas legales a su alcance para restringir la captación de prosélitos. Así, no incluyó la ley de Honorio del año 416 (C. Th. XVI, 2, 23) que permitía al judío converso la vuelta a su antigua religión si se arrepentía del paso dado, y prohibió a los judíos molestar a sus antiguos correligionarios convertidos al cristianismo (L.R.V. $X V I, 3,1)$. A los cristianos convertidos al judaísmo los castigó con la pérdida del derecho a testificar (L.R.V. XVI, 3, 2). Se mostró especialmente duro en el castigo por la práctica de la circuncisión (L.R.V. Sent. Pauli V, $24,3-4)$, lo que tal vez haya que considerar influencia del pensamiento del obispo Maximino. A los ciudadanos romanos que permitieran les fuera practicada (o a sus esclavos) se les castigaba con la deportación y la confiscación de sus propiedades; y con la muerte al médico encargado de realizarla, o al judío que circuncidara a un esclavo no judío. Como la circuncisión acabó por convertirse en marca distintiva de esclavitud, Ala-

73 Jones, Later Roman Empire, II, pág. 946. 
rico intentó evitar que sus súbditos judaizaran practicando dicha operación a sus esclavos. Por eso decidió conceder la libertad a los siervos circuncidados (L.R.V. XVI, 4, 1), y permitió que cualquier cristiano pudiera rescatar a un esclavo de su misma religión que fuera propiedad de un judio, aunque se hubiera convertido al judaísmo (L.R.V. III, 1, 5). La debilidad jurídica y moral de los esclavos hacía de ellos seres especialmente susceptibles de ser captados para el judaísmo. Igual ocurría con las mujeres: la L.R.V. III, 7, 2, prohibió los matrimonios mixtos y la L.R.V. IX, 4, 4, en realidad una reiteración de la anterior, aplicó a los judíos la lex lulia sobre el rapto y el adulterio, que consideraba adúltera la unión matrimonial entre judío y cristiana, o entre cristiano y judía.

Dada la influencia que tuvo el obispo Cesáreo de Arles en la redacción de este cuerpo de leyes ${ }^{74}$, podría pensarse que todas las medidas tomadas para prevenir el proselitismo judío tendían a beneficiar a los cristianos. $Y$, en efecto, fue así, aunque Alarico utilizó los resquicios que le quedaban para mejorar en lo posible al arrianismo. El Br eviario no incorporó la ley del Código (XV I, 5, 5) que imponía a los judíos ciertas obligaciones durante las festividades cristianas, con la evidente intención de que cada grupo guardara sus propias fiestas y que no fuera la jerarquía católica la que marcara el ritmo diario de la vida ${ }^{75}$. No obstante, las características de la religiosidad germánica no hacían probables numerosas conversiones de arrianos al judaísmo. Por tanto, a Alarico II le debieron mover otras razones de mayor peso para tratar discriminadamente a la religión judaica. Bruck opina ${ }^{76}$ que la elaboración de la Lex Romana Visigothorum y las modificaciones que en ella se hicieron con respecto a la legislación romana anterior estuvieron de acuerdo con los cánones del Concilio de Agde, concluido unas semanas antes, dado que fueron alterados sólo aquellos textos por los que la Iglesia católica estaba interesada. Ya hemos visto el problema que tenía planteado esta institución con la tendencia a la judaización entre sus feligreses $y$, sobre todo, en aquellas zonas de mayor densidad hebrea, como eran Provenza y Narbonense. De hecho, hacía años que se venía viendo el problema porque los Statuta

${ }^{74}$ A finales del invierno del año 503 Cesáreo se encontraba alejado «in Burdigalensem civitatem... quasi in exilio relegatus" (Vita Cesarii, I, c. 17), según se deduce de la fecha de la Epist. IV de Ruricius. Pero Alarico contó con su opinión y le mandó a altas personalidades de su círculo de visita, como el propio obispo contó a su amigo Ruricio en la Epist. III.

75 En cuanto Recaredo abrazó públicamente la ortodoxia, el concilio de Narbona, celebrado el mismo año 589, les obligó, en el c. 4, a que observaran las fiestas cristianas y les impidió trabajar los domingos; si bien es cierto que la disposición eclesiástica no recibió confirmación real por lo que no adquirió fuerza de ley.

76 Bruck, E. F., "Caesarius of Arles and the Lex Romana Visigothorum", Studi in onore di Vicenzo Arangio-Ruiz. Nápoles s.a., págs. 211 y 214. 
Ecclesiae antiqua, compilación de textos disciplinares de esa zona de hacia el 475, recomiendan en su canon 16 que los obispos traigan a los judíos a la iglesia para que oígan la palabra de Dios ${ }^{77}$ y que se les permita su permanencia en ella hasta finalizada la Misa de los catecúmenos; y en el canon 83 prohíben que los cristianos guarden las festividades judías, advierten contra sus supersticiones y prohiben que el clero cristiano fabrique y haga uso de las filacterias (c. 36), suerte de amuletos que tenian la misión de actuar como cadena de las almas. En opinión de Ber$\operatorname{man}^{78}$, éstas no eran realmente prácticas propias del judaísmo oficial, sino de extrañas y curiosas sectas sincretistas, a las que los judíos galos pertenecian en gran número: lo que justificaría la falta de teólogos y rabinos hebraicos a que hemos hecho alusión. En el año 506 el clero reunido en Agde, el primer concilio general del reino de Tolouse, inició la política de segregación y endureció su actitud hacia los judíos, con el objeto de evitar que muchos pudieran convertirse por conveniencia, y otros siguieran atrayendo cristianos al pueblo de Israel con el señuelo de sus vistosas ceremonias. Así el canon 34 elevó a ocho los meses de catecumenado para comprobar que el judío renunciaba definitivamente a sus antiguas prácticas, y el canon 40 prohibió a los sacerdotes y laicos cristianos comer con los judios, lo cual estaba siendo muy frecuente en la celebración del sabbath.

No nos cabe la menor duda de que Cesáreo de Arles hizo un pacto político con Alarico en los críticos meses previos al desenlace de Vouillé. Tres años antes su secretario, Liciniano, le había denunciado al rey por haber querido entregar Arles al rey de los burgundios, de quien era súbdito por nacimiento, lo que obligó a Alarico II a exiliarle de Burdeos. En el año 506, Cesáreo aprovechó el acoso de los francos para intentar recuperar a sus feligreses perdidos. Debió prometerle su apoyo de metropolitano y el del resto del clero y de la feligresía, a cambio de que el rey frenara con su legislación civil, la única que podía alcanzar a los judíos, su irresistible aumento numérico, y Alarico, cercado por francos y burgundios, dos pueblos germánicos a punto de convertirse a la ortodoxia tuvo que ceder. Los judíos no guardaron rencor a los godos por ello, como demuestra el que se les confiara la defensa de una parte de la muralla de Arles en el asedio de Gundebaudo del año 508, si bien es fácil también que la legislación del Breviario no recibiera plena aplicación y por eso, en contra de la L.V. Novella III de Teodosio, tomaron las armas.

\footnotetext{
${ }^{77}$ Statua Ecclesiae antiqua, Corpus Christ, Seriea Latino t. CXLVIII, pág. 169 (ed. de C. MUNIER Y $P L, 882$.

${ }_{78}$ Berman, L., Histoire des Juifs de France des origines à nos jours, pág. 15.
} 
En los años inmediatamente posteriores del intermedio ostrogodo y de la conclusión de la etapa arriana no parece que se les aplicara ninguna restricción más, dado que no existe ninguna Antiqua que aluda a ellos. Su número siguió creciendo y fueron parte importante del componente demográfico de la Septimania, único reducto de la Narbonense conservado por los visigodos tras la cesión de la Provenza, en 526, a los ostrogodos a cambio de la recuperación de su soberanía ${ }^{79}$.

79 El Concilio III de Narbona (año 589), en los c. 4 y 14, menciona a los judíos entre los componentes de la población provincial: gothus, romanus, syrus, graecus vel iudaeus. Creo que se trate más bien de una enumeración religiosa que étnica, pues si los judíos eran romanos no se comprende tal distinción. Otras fuentes, como la Insultatio de Julián de Toledo ( $P L, 96, \mathrm{col}$. 794) constatan su importancia numérica y, gracias a una carta del obispo Agobardo de Lyon, de época carolingia, sabemos que los hebreos de la zona conservaron las relaciones cordiales con los cristianos y, en concreto, con su obispo Nebridio (Epist. 9 ad Nibridum, MGH, Ep., V, 199-200). 